\title{
LGBT, Nature or Ideology?: Sharing the Experience of a Former Practitioner in Malaysia
}

\author{
${ }^{1}$ Dr. Musa Yusuf Owoyemi, ${ }^{2}$ Dr. Ahmad Zaharuddin Sani Ahmad Sabri \\ ${ }^{I}$ Visiting Senior Lecturer, Centre for General Studies, College of Arts and Sciences, Universiti Utara Malaysia \\ ${ }^{2}$ Senior Lecturer, Centre for General Studies, College of Arts and Sciences \\ Universiti Utara Malaysia
}

\begin{abstract}
This research discusses the issue of LGBT in the Malaysian society by sharing the experience of a former practitioner of the sexual orientation described generally as LGBT.

Using the qualitative method of interview and textual analysis of the interview, the research ask the question of whether this sexual orientation is a natural phenomenon or an ideology propagated by certain quarters as is the practice in the contemporary time.

The findings of the research through the interaction with the former practitioner of this sexual orientation show that the issue is a double edge sword which requires caution and understanding from the larger society. However, the research shows that it is not something that is insurmountable as is being portrayed in certain quarters.
\end{abstract}

Keywords: LGBT, Nature, Ideology, Malaysia, Society, Religion, Experienced LGBT,

\section{Introduction}

The issue of Lesbian, Gay, Bisexual and Transgender (LGBT) has its origin in the narration of the scriptures - that is the Torah, the Bible and the Qur'an. Although the accounts of these holy books talks specifically about the sexual relationship between men, the moral of the stories in the holy books is that all sexual activities that involve same sex is unnatural and thus prohibited by God, the giver of laws. The Torah, the Bible and the Qur'an say as follow:

Thou shalt not lie with mankind, as with womankind; it is abomination. Lev.18:22

And if a man lie with mankind, as with womankind, both of them have committed abomination: they shall surely be put to death; their blood shall be upon them. Lev.20:13 (Carrol \& Prickett, 2008).

And likewise also the males, leaving the natural use of the female, burned in their craving toward one another, males with males committing unseemliness and fully receiving in themselves the retribution of their error which was due. Roman 1: 27 (Carrol \& Prickett, 2008).

We also sent Lut : He said to his people : "Do ye commit lewdness such as no people in creation (ever) committed before you? For ye practice your lusts on men in preference to women: ye are indeed a people transgressing beyond bounds." Qur'an 7:80-81

What! Of all creatures do ye come unto the males, and leave the wives your Lord created for you? Nay, but ye are forward folk. Qur'an 26:165 (Pickthal, 1953).

In other words, although the practice at the time of Sodom and Gomorrah is for a man to have sexual intercourse with his fellow man, in Islam, by analogy the prohibition of this relationship also applies to Lesbianism (i.e. the art of women having sexual relationship with a fellow woman) and Bisexualism (i.e. a man or woman who engages in sexual relation with the opposite sex and their own kind). In the hadith, there is a categorical prohibition against Lesbianism by the Prophet as he was reported to have said: "Lesbianism by women is adultery between them" (Tabarani, sahih) (Keller, 1997: 664 - 665).

As for Christianity, the prohibition of Lesbianism and Bisexualism are explicitly mentioned in the Bible Roman 1: $25-27$ which says as follow:

Therefore God gave them up in the lusts of their hearts to uncleanness, so that they dishonour their bodies among themselves, Who exchanged the truth of God for the lie, and worshipped and served the creation rather than the Creator who is blessed forever. Amen. Therefore God gave them up to passions of dishonour for their females exchanged the natural use for that which is contrary to nature; And likewise also the males, leaving the natural use of the female, burned in their craving toward one another, males with males committing unseemliness and fully receiving in themselves the retribution of their error which was due (Living Stream Ministry, 1991).

In Judaism, the same also applies. In fact, the story of Sodom and Gomorrah, which is the basis of the prohibition of same sex sexuality, was first told in the Torah, which is the scripture of Judaism, in Genesis. Later 
it was explicitly stated in Leviticus 18 and 20 that same sex sexual relationship is unnatural and henceforth prohibited. But, as in Islam, this ban applies to Lesbianism and Bisexualism by analogy.

Talking about Transgender, it is defined as describing "a range of people with conflicts or questions about their gender. They include people who are born male but think themselves female, or vice versa, or people who are preparing for a sex change operation, or those who have had a sex change" (Russo, May 29, 2005). In other words transgender is seen as a process in which a person undergoes Sexual Reassignment Surgery (SRS) in order to change his/her sexuality to the opposite sex either because the person's behaviour, disposition and appearance resembles that of the opposite or because the person is born as an hermaphrodite or the person deliberately wants to change to the opposite sex or because the person has conflict with his/her feelings and biological body.

However, the research on gender appears to be based on men's experiences and showing that it is a complex issue (Faulkner, 2002) which sometimes focuses the women but is not seen to influence or impact upon men. This implies that gender is considered in heterosexual terms alone, where heterosexuality is tacitly regarded and accepted as the norm. In other words, women are often considered in relation to a typical family unit comprising one male and one female parent with one or more children. Moreover, gender and sexuality can be seen as separate set of things that closely blended at many points with cultural logic that is combined with many other components to form a fully articulated social identity (Ben et al., 2008). Thus, some formations have been derived from identities through sexual orientations, leading to the existence of Lesbianism, Gayism, bisexualism and transgenderism (LGBT). Indeed, it is claimed that assumptions and norms associated with sexualities closely contribute to the meaning of contemporary culture and society.

In the light of all the above, this paper is an attempt to look at the issue of LGBT through a practitioner of one of these sexual orientations by delving into the debate about whether this sexual orientation is innate to those who practice it or an ideology adopted by certain people.

In order to achieve this aim, the paper first looks at the root of LGBT in Malaysia by quoting the view of the leaders of the nation who grapple with the existence of these people in the nation. Second, it tries to bring the issue into focus by interviewing an experienced LGBT who have reverted to straight less than three years ago. Third, it analysis the interview of the Experienced LGBT on the issue; and fourth, it shows the result from the findings in the interview. Finally, the conclusion reached at the end of it all.

\section{The Root of LGBT in Malaysia}

Although Malaysia is a multi-ethnic and multi-religious nation, nonetheless, Islam is officially recognized as the religion of the state. Islam, being a religion which out-rightly forbids same sex relationship or any unnatural relationship among human beings has in its penal code, punishment by death for anybody who engages in this activity. This being the case, it is expected that naturally, since the Islamic law applies in the nation, the issue of LGBT is not allowed. In fact, the Shariah court has the mandate to act against any individual or group who engage in any unnatural sexual relationship (The Constitution of Malaysia).

In addition to this, the penal code that Malaysia inherited from the colonial masters has a provision against the practice of unnatural sexual relationship among human beings in section 377. This law prohibits unnatural and anal sex and it has been invoked in certain cases in the nation (ibid.).

The above being the case, one would have expected that Malaysia, having provision against LGBT both in its Shariah and common law would be free from this practices. But this is not the case as the issue is present in the nation and has become of public concern with some people openly campaigning for their rights to practice and engage in relationships described as LGBT - believing that as long as it is consensual between two adults it is part of their fundamental rights to practice it. Thus, the question is, what is the cause of this practice and where does the encouragement come from? Likewise what is the effect so far on the nation?

In answering the question above, one has to look at the changes going on in the world generally in terms of the fight and clamour for human rights and the encroachment of modern western liberal ideology on many nations of the world including Malaysia. The spread of liberalism (an ideology that develops during the enlightenment which preaches liberty and equality among mankind and advocates freedom for mankind to use his/her reason to behave the way they deem fit as long as it does not impinge on the rights of others) coupled with the universal declaration of human rights by the United Nations are two important elements which work in the favour of LGBT and they serve as the reference point in the spread of the LGBT practices in many nations.

Collaborating the above as it relates to Malaysia, speaking at a workshop for counselors on the issue of LGBT in Malaysia Dato' Hj. Shahlan Hj. Ismail, the Chairman of PIBG in Putrajaya says liberalism is at the centre of the encroachment of LGBT in Malaysia. In his submission, he posits that liberalism emphasizes three important things and these are: (1) it sees "individual freedom as supreme"; (2) it "emphasizes personal rights and equality of opportunity"; and (3) view "struggle for freedom of behavior, ownership, expression and religion" as very important (Hj. Ismail, March 14, 2013). Thus, he says, LGBTs capitalize on this to claim their right to freely express their sexual freedom and orientation (ibid.). 
The fact above was further established when the Prime Minister of Malaysia, Najib Abdul Razak, warns, against the encroachment of liberalism and pluralism in Malaysia and hints of the government resolved to fight the scourge (Malaysiakini, June 26, 2012). However, one can say, as earlier mentioned, that this was further helped by the contemporary emphasizes on human rights as contained in the United Nations document for the declaration of fundamental human rights. The LGBT issue has been reduced to the issue of human right and personal freedom, thus, many NGOs now champion the cause of the LGBT community in many nations including Malaysia. This fact explains why the Malaysian Prime Minister opposed the inclusion of LGBT rights in the ASEAN declaration of human rights as he points out that "It depends on your values and norms and we reject LGBT but it does not mean any weakening in terms of the principle of human rights," in fact, the Prime Minister says that "we feel that the declaration has points which are better than the universal declaration of human rights" by the United Nations (Zulfakar, November 19, 2012).

The effect of LGBT on the nation is the proliferation of LGBT activities and the conversion of many unsuspecting teenagers to this sexual orientation. In Malaysia, there are now clubs and organizations that represent and protect the rights of the LGBT community and this has resulted in a situation in which schools and the public spaces are daily being invaded by LGBTs. One of such LGBT organization known as Seksualiti Merdeka (Sexual Independent) now organizes annual events to highlight the fight for recognition by the LGBT community in Malaysia.

The development above prompted the Prime Minister Datuk Seri Najib Razak, to warn against the culture of LGBT and the ideology of liberalism and pluralism in the nation saying "We will ensure that any deviant culture, such as the behaviour of the LGBTs and deviant thoughts such as liberalism and pluralism, will not get any place in this country," (Malaysiakini, June 26, 2012). In addition to this, the government came up with certain policies in order to curb the spread of this practice and the ideologies of liberalism and pluralism in the nation. Some of these policies include: the government shutdown of the November 2011 Seksualiti Merdeka (Sexual Diversity [Independent]) Festival; a government program to train volunteers to "convert gays;" and the public recommendation by Deputy Education Minister Dr. Mohd Puad Zarkashi that educating parents to recognize "symptoms" of gay or lesbian orientation could be effective in fighting increase of this "unhealthy phenomenon among students" (Human Right Watch, December 5, 2012). Recently, the government also organizes a musical tour to enlighten students about the bad habit of LGBT; it organizes seminars for parents on how to recognize gay and lesbian symptoms in youths; and did a seminar on how to correct the effeminate behavior of schoolboys (Hodal, March 28, 2013).

Thus, from the above, the government recognizes the fact that liberalism, human rights and the encroachment of modern western ideas in the nation are the factors which promotes the ideology of LGBT and it has resolved to take on this issue head on as it is apparent from some of its program which are meant to enlighten the people especially the youth about the dangers of this orientation and the fact that it is against their worldview as Muslims and a nation which is emphasizes its religious heritage. In this vein, the Deputy Prime Minister Tan Sri Muhyiddin Yassin, was reported to have "warned Muslims today of LGBT advocates who are said to be "poisoning" the minds of Muslims to accept "deviant practices" in the name of human rights" (Zurairi, April 22, 2013). He says further: "We cannot be careless, the challenge against Islam's position comes in many ways... There are parties who are becoming more strident in demanding freedom of religion without limits, including the right for Muslims to become apostates," and "to accept "deviant practices" in the name of human rights" (Zurairi, April 22, 2013).

\section{LGBT: Nature or Ideology?}

From the discussion above, what is apparent is that religion and society view the problem of LGBT as an ideological one or something that a person willingly accepts as a way of life as is seen in the narrations from the holy books and the views of leaders of society. However, there are others who hold that the issue of LGBT is a natural thing that is inherent in the nature of those who practice it (Kugle, 2003; Jamal, $2001 \&$ Malik, 2013). They hold that like normal sexual orientation or straight, same sex attraction is natural to those who practice it because it is what they feel in their nature which is inborn to them (Teh, 2001). According to this line of argument, these people are entitled to enjoy their sexual orientation just as those who are straights are entitled to theirs (Kugle, 2003). Moreover, Jamal (2001) points out that most of the verses that are quoted to support the prohibition of same-sex marriage from the Qur'an, for example, are not verses that refer directly to the issue but were extended by exegetes to include the prohibition of same-sex marriage. As for the transgender, it is generally held that it is a case of people who find themselves trapped in a body that they do not feel that they belong to and as such have the right to express their sexual preference even if it is conventionally seen as wrong. In the light of the above, this research is an attempt to get to the root of the issue by finding out from a practitioner of LGBT whether the issue is ideological or natural as posited by the two views above. 


\section{Qualitative Research Paradigm}

The field study uses qualitative research technique through semi structured interview in order for the researcher to have full understanding of perception of LGBT people before and after engaging in their distinctive lives. The review of the literature provided the framework for initial development of the interview questions and helps in refining the interview questions to better suit the LGBT domain. Interview mode of gathering data is an effective tool to collect data from group or individual respondents and provides the quick and detailed link to the root of the research (Creswell, 2003; 2012). Moreover, a convenience sampling method is adapted in selecting the sample for this research which helps us in selecting the best person to produce the best answers to our research questions. Indeed, the main objective of this paper is to determine whether LGBT is a natural or an ideological issue.

\section{Interview Sample Demographics}

The data collection in this research was conducted by granting interview to only one experienced LGBT through convenient sampling approach due to the difficulty in finding the experience LGBT to be interviewed voluntarily. Though, convenient sampling is quiet acceptable in business research and view as an act of taking an available and useful sample for ease data gathering (Joan and Donald, 2010; Bart et al., 2010; Sherri, 2011). Meanwhile, the participant was selected on the basis of his characteristics which could help in producing insights and understandings of the research objectives and summarized in Table 1.

\begin{tabular}{|l|l|}
\hline \multicolumn{2}{|l|}{ Participant's Detail } \\
\hline Current Age & 36 years \\
\hline Current Education Status & Diploma holder \\
\hline Occupation & Teacher cum Entrepreneur \\
\hline Parents' Job & Entrepreneurs \\
\hline Age when he joined LGBT & 17 years \\
\hline Parents' Family Size & 5 \\
\hline Duration of Participating in LGBT & 19 years \\
\hline
\end{tabular}

Furthermore, the respondent was first introduced to us by the counselor who took charge of his case. Second, we sat down with him and had an interview session of thirty minutes because of his tight schedule that day and the fact that he has to give a talk and interact with others who are seeking help like him. Third, he was contacted by telephone and further interviews were done through this channel.

The objectives of the study were explained to him and he agreed to cooperate fully with the researchers. The respondent who happens to be an experienced LGBT took part in this interview on a voluntary basis. He was able to tell us his background; academically, family issue and the life spent in the LGBT domain. The respondent is regarded as a formidable person when it comes to the talk on LGBT.

\section{Interview Sessions with Experienced LGBT}

The interview was conducted between the researcher and the counsellor on Thursday, $7^{\text {th }}$ of April, 2013. Many questions about the LGBT issue were asked the experienced LGBT and the answers were provided as follow:

\section{Question}

Is the problem of LGBT a disease or natural as they used to say?

\section{Answer}

(Experienced LGBT)

The problem of LGBT is not a disease but is one of the tests from Allah which tells human on how to control the specialization given to individual by Allah. That is why the sex emotion in LGBT world is given focus so as to help them on how to overcome these unique characteristics, even though they were born with it.

\section{Question}

There was a story of a woman with two children. She said each time she was with her husband, she does not have feeling of being together and eventually broke-up the marriage and bisexual. What is really causing this issue and is it natural?

\section{Answer}

(Experienced LGBT and a counsellor)

This is mainly caused by instinct with the woman. It is not natural but this may be cause if someone is exposed with sexual engagement before marriage which may prevent him or her from being honest with the spouse. The easiest way to solve this problem is for the affected person to inform his or her partner about his sex emotion.

\section{Question}

Does it mean that the affected people are not born with this menace?

\section{Answer}

This can be view in two different ways: 
1. The LGBT could be cause by the experience with sex abuse which may be difficult to leave after having a bisexual experience.

2. Some people were born deeply inside with sex emotion and once they could not control it, they would turn to transgender. This can be control by spending time with positive people and reading Al-Qur'an always.

\section{Question}

Is it true that a man can feel that is not a man right from his childhood?

\section{Answer}

(Experienced LGBT)

This kind of problem has happened to me. I was born as a man but presenting myself as a woman because of sex emotion in me and not because of any sex organ.

\section{Question}

How do you feel when you interact with people in the society when you were in the LGBT world?

\section{Answer}

\section{(Experienced LGBT)}

My relationship with other sect of people was limited because of the society i belong to. I felt they cannot understand me because they cannot offer what $i$ want. I felt i do not belong to other people and we discriminate a lot. However, the LGBT people need to be given hand of love and caring in order to bring them back to the normal life.

Question

How do you feel now that you are no more in LGBT world?

\section{Answer}

(Experienced LGBT)

Now that my life has been transformed, i can move with people and have good interaction with men and women in the society.

\section{Question}

Why is it that the LGBT people do not have confident in themselves to interact with others in the society?

\section{Answer}

(Experienced LGBT)

This is because they think they are very special and they always are scaring of the judgement which they feel people can incur on them. They believe that a special people should communicate with special ones.

Question

Do you agree that there is conflict with what the LGBT are and what they feel?

\section{Answer}

(Experienced LGBT and a counsellor)

Yes. There is serious conflict in the two terms when it comes to the LGBT world.

\section{Question}

Do you think for once that your body was not the real type when you were in LGBT world?

\section{Answer}

(Experienced LGBT)

Yes i believe that my body was not really and started taking some pills and injection in order to do the transformation. But, i give thanks to Allah because i can come back to the normal way of life. I have grown spiritually and inspiration from the creator, showing that other people in LGBT can change to better one.

\section{Question}

What do you think is the long time effect of the LGBT people?

\section{Answer}

(Experience LGBT)

Based on my experience, this brings about life term psychological effect on the LGBT. It also affect mental and emotion because it affect Allah's in junction and writing in the holy book. Many of my friends have ruined their life due to the medical operation they have involved in the name of becoming LGBT.

\section{Question}

Finally, how can a person from the LGBT world live a normal life?

\section{Answer}

The person has to change by moving with positive people like my counselor. The person should also read the Qur'an, practice Tawba and try not to move with negative people who will influence him especially about sex.

\section{Second Interview on Phone}

\section{Question}

When did you start noticing that you have this sexual orientation?

\section{Answer}


Well, it starts when I was five. I used to cross dress and my parents noticed this. They also notice that I am different in a way.

Question

You mean it is just natural or it starts naturally?

Answer

Yes, I just notice that I feel different from what I am. And I tried to suppress this feeling. But the problem is there is no one to help me. Even when I was around ten years old, I tried to live normally but no one to help. Even my own brother sees me as useless because of the way I am. So it is kind of difficult you know?

Question

So, when did you start practicing fully as a transgender?

Answer

I start when I entered college

Question

How old where you then?

Answer

I was about $17 / 18$ years

Question

Were your parents aware?

Answer

Yes, they know and they give me their support. They never discriminate me because they understand me.

Question

Now, after so many years, why did you decide to change?

Answer

The truth is we may pretend to be happy, but deep down we are not happy because of the society and the rejection that we face. Moreover, this thing is against religion and it is like a test from Allah so we have to know how to overcome the sexual urge like all others.

Question

Do you still move with your group?

Answer

I try to be friend with them and to show them that they can change like me. But I also try to move with people who are positive because if not I can easily be influenced to go back. When I was still transgender, the discussion is always about sex! Sex!! Sex!!! So I try to move with positive people.

Question

So you are saying that the ideology is always about sex?

Answer

Yes, the talk is always about that and this influence us a lot.

Question

So you are saying this issue is also about ideology not just nature?

Answer

It is both. It is natural and also because of the group it is also ideology about sex. In the group the idea is all about sex and they teach you to practice this sex idea.

\section{Data Analysis Using Textual Analysis Approach}

From these two interviews above, it is clear that the issue of LGBT revolves around nature and ideology - and one can also add circumstances in the case of those who were traumatised by their unusual sexual experience as in the case of sex abuse victims. As the Experienced LGBT points out, there are some people who are born with this sexual orientation and to such people the issue is that of nature. It is a natural instinct in them. However, from his experience, it is clear that this set of people can overcome this sexual instinct if necessary help is extended to them and they are encouraged by the society through positive interaction. The instinct is like any other instinct in man and it is possible to control it. The instinct to be greedy, to steal, to hate, to love etc are all present in man just like the sexual instinct and they are liable to control given the right environment and interaction. Therefore, in this sense, from what was pointed out by the Experienced LGBT, it is possible to control the sexual orientation described as LGBT even if it is inborn in a person. This, as is apparent from his case, is why he was able to come out of the practice through the help of his counsellor and through being with those who encourage him in religion and its practices.

What is clear, therefore, from the above is that people whose sexual orientation are LGBT could have been born with such sexual instinct and in this case it is natural or nature at work. However, since it is conventionally an abnormality, like all abnormalities, it deserves to be treated as such and people who fall in this category needs to be helped and not condemned by society. As the Experienced LGBT pointed out, if he 
had received help from the beginning, he would not have ventured into it at all and he would have over come the problem right from its early stage. This shows the failure of society in this respect and the need for a program to help people who are identified as LGBT at the early stage before it grows with them. As the Experienced LGBT said, the problem is not a disease but an abnormality which could be corrected.

Second, the Experienced LGBT talks about another category of people who are inclined to practice this sexual orientation as a result of the sexual abuse that they were subjected to when growing up. In this case, it is not a case of nature but circumstances which gradually lead to habit. This people can also overcome this problem too since it is not inborn but an habit formed as a result of their circumstances of sexual abuse. In other words, since it is circumstances that made them to be inclined towards this sexual orientation, what these set of people need is rehabilitation and reorientation about their sexuality which means that through proper counselling and therapy, they could also overcome it - especially since it is not inborn.

Third, the Experienced LGBT talks about the issue of ideology in the spread and practice of this sexual orientation. This shows that the ideology of free sex and all form of sex as natural is a catalyst in the spread of this sexual orientation. The problem here, from the interview, is that those who propagate this ideology do not give the people described as LGBT the opportunity and chance to overcome their unconventional sexual attitude, thus, making them believe that they are a special category of people pitted against the normal conventional people. This is where the whole problem of LGBT lies in the contemporary time. The ideology of liberalism as it concerns sex and sexual orientation is behind the boldness and attitude of many LGBT in coming out and declining to change and get help for this abnormality. Through the concept of liberalism and human rights, the society is being forced to accept abnormality as part of human sexuality and organisations and activists are also helping to promote this ideology in the name of freedom. Although, it is true that society needs to accept the fact that LGBTs are special category of people who are different from them because of certain trait/instinct that they have. Nonetheless, instead of allowing them a free reign in spreading this abnormal instinct in them and even incorporating those who are not born with this instinct, it is the duty of society to help them overcome the instinct by providing necessary help through counselling and therapy and also through religious activities which could play a positive role in helping them to see that their desire for this kind of sexuality is a test which they have to pass by overcoming it as expressed by the Experienced LGBT during the interview. Thus, sexual ideology or the ideology of all forms of sexual orientation is right is also behind the LGBT issue as it could serve as a temptation for those who like to experiment and the adventurers who out of curiosity would want to experience everything and anything. This, perhaps also explain the new wave of youths' conversion to this sexuality in droves by clubs and organisations which propagate this sexual ideology. This finding also confirms the government stand on the issue that it spread in the society and especially among the youths is due largely to it being adopted as an ideology by certain people.

\section{Result from the Research}

From all the discussions above, what we found out from the research is that the issue of LGBT is a multi-fold one which also needs a multi-fold approach. The assertion by some researchers that it is natural and inborn is true since, from the experience of our interviewee, it is innate to him and thus a natural phenomenon. However, as he asserts, like all other instincts in man it is subject to control given the proper environment, counselling and therapy. In other words, it is something that could be overcome like any other negative instinct in human beings.

Second, some people find themselves in this sexuality by circumstances which are related to sexual abuses and thus practice it as a result of their personal experience. In this case, the individual could also be helped given the right treatment especially since it is not innate to them but developed out of habit.

Finally, there are others who are explorers and who are converted to this sexual orientation as a result of their interaction with people who practice and propagate this sexual ideology. In the case of this, as in the case of the group above, all that is need is a reorientation because their practice of the sexuality is also borne out of habit. Moreover, the case of this group confirms the government assertion that it is also an issue of ideology and not only nature. Thus, the government needs to act against those who propagate this sexuality and curb their activities which are harmful to the society at large.

\section{Conclusion}

The issue of LGBT is both nature and ideology. It is nature because some people are born with the innate instinct of having sexual feelings for people of their sexual kind. In their case, like 'poles attract'. Likewise, some people are born innately feeling that they are in a wrong body because they feel that their sexuality is that of the opposite sex and not in the body that they found themselves. In this case, there is a need to create equilibrium in the person by making what he/she feels equal to what he/she is. LGBT is also an ideology because some people are converted to this ideology as a result of their experience. The experience could be in form of sexual abuse or interaction with group which advocate this sexual orientation. 
However, in both of the cases, it was found out that LGBT practices is something that could be overcome by the practitioner if he/she is willing to overcome it. We argued from the interview that the issue of LGBT is related to man's sexual instinct which is like any other instinct in mankind and is subject to control through discipline, counselling and the right therapy.

Religion is also a vital mechanism for controlling this sexual orientation. Since religion is plainly against this sexual orientation, it could be used as a form of therapy for the prevention of the practices and help the person to be come more spiritual and move closer to God as the interviewee alluded to in his case.

The parents, society and government have vital roles to play in helping the people who are described as LGBT. The parents need to know their children and detect early warning signs of this sexual orientation in their ward. If they are able to do this, they could easily seek for help for the child and nip the instinct in the bud before it grows. As for the society, there is need for people to embrace this category of people and try to help them overcome the problem. As the interviewee said, the rejection and stereotyping of these people make them to recoil into their shell and find a save haven among their peers thereby depriving them of the opportunity to interact with the others in the society and seek for the necessary help that they need. Finally, on the government side, there is need for government to act against groups who propagate this sexual orientation and seek to convert others to it since their action confirms government stand that this sexual orientation is being spread as an ideology. Likewise, there is need for a concerted program in form of seminars, films, radio and television campaign etc in order to make people to beware of the activities of groups who propagate this ideology as well as where people could get help for themselves, their wards, friends, and relatives etc.

\section{References}

[1]. Bart, L.W., Christopher, J.L.C. \& David, J.P. (2010). Understanding Business Research. Canada: John Willey and Sons Inc.

[2]. Ben, L., Gordon, F. \& Alison, A. (2008). "Gay men, Gaydar and the commodification of difference" in Information Technology \& People, Vol. 21, No. 3, pp. 300-314

[3]. Carrol, R. \& Prickett, S. (eds.) (2008). The Bible: Authorized King James Version (Oxford World's Classics). Oxford: Oxford World's Classics.

[4]. Creswell, C. W. (2012). Qualitative Inquiring And Research Design: Choosing Among Five Approaches. California USA.: Sage Publications Inc.

[5]. Creswell, C. W. (2003). Research Design: Qualitative, Quantitative and Mixed Method Approaches: Second Edition. California USA.: Sage Publications Inc.

[6]. Faulkner, W. (2002), "The power and the pleasure? A research agenda for "making gender stick" in Science, Technology and Human Values, Vol. 25 No. 1, pp. 87-119.

[7]. Hendricks, M. (July 2006). "Islam and Homosexuality" in ILGA's preconference on religions. doc.Ilga.org/content/download/4522/27322/version/1/file/ILGA-July06-Religions.pdf $\quad$ accessed May 3, 2013.

[8]. Hj. Ismail, H. S. (March 14, 2013). "Liberalisme: Cabaran dan Ancaman Masa Kini". Seminar Keibubapaan Menangani Isu LGBT. Alor Setar, Kedah: Al-Bukhary International University.

[9]. Hodal, K. (March 28, 2013). "Anti-gay Musical tours Malaysian Schools and universities” in The Guardian. UK.: The Guardian Newspaper.

[10]. Human Right Watch, (December 5, 2012). 'Moderate' or Fraud: Najib Slammed for attacking for Political Motives" in Malaysia Chronicle. http://www.malaysia-chronicle.com/index.php?option=com_k2\&view=item\&id=44738:moderateor-fraud-najib-slammed-for-attacking-lgbt-for-political-motives\&Itemid=2 accessed May 3, 2013.

[11]. Jamal, A. (2001). "The Story of Lut and the Qur'an's Perception of the Morality of Same-sex Homosexuality, 41 (1). Taylor and Francis, Routledge.

[12]. Joan, C.C. \& Donald, R.M. (2010). Handbook of Gender Research in Psychology. Volume 1 and Experimental Psychology. Springer.

[13]. Keller, N. H. M. (ed. \& trans.). (1997). Reliance of the Traveller: A Classic Manual of Islamic Corporation.

[14]. Kugle, S. S. H. (2003). "Sexuality, Diversity, and Ethics in the Agenda of Progressive Muslims" Justice, Gender and Pluralism, edited by Omid Safi. U.S.A.: OneWorld Publisher.

[15]. Living Stream Ministry. (1991). The New Testament: Recovery Version. California: Living Stream Ministry.

[16]. Malaysiakini ( June 26, 2012). Najib: No Place in Malaysia for LGBTs. http://www.malaysiakini.com/news/201913 accessed May 3, 2013.

[17]. Malik, F. Queer Sexuality and Identity in the Qur'an and Hadith. http://www.well.com/user/aquarius/Qurannotes.htm accessed May 5, 2013.

[18]. Pickthal, M. M. (1953). The Meaning of the Glorious Qur'an: An Explanatory Translation. U.S: Signet, Trade Paperback.

[19]. Rowson, E. K. ((Oct. - Dec., 1991). "The Effeminates of Early Medina" in Journal of the American Oriental Society, Vol. 111, No. 4. p. 671-693.

Russo, E. (May 29, 2005). "Eugene City Beat: Transgender Law Proposal to get Airing" in The Registered Guard. http://members.efn.org/ lanegq/media/2005.05.29_Transgender_law_proposal_to_get_ai ring.txt accessed May 2, 2013

[20]. Sherri, L. J. (2011). Research method and statistics: a critical thinking approach. $4^{\text {th }}$ edition, wadsworth cengage learning, Belmonth CA., USA.

[21]. Teh, Y. K. (2001) Mak Nyahs (Male Transsexuals) in Malaysia: The Influence of Culture and Religion on their Identity. IJT 5,3. http://www.safraproject.org/downloads/Mak_Nyahs- Malaysia.pdf accessed May 7, 2013.

[22]. The Constitution of Malaysia http://confinder.richmond.edu/admin/docs/malaysia.pdf accessed 2013.

[23]. Zulfakar, M. (November 19, 2012). "Asean Leaders Ink Declaration” in The Star. Malaysia: The Star Newspaper.

[24]. Zurairi, A.R. (April 22, 2013). "Beware of LGBT and Freedom of Religion Movements, Muhyiddin tells Muslims" in The Malaysianinsider. http://www.themalaysianinsider.com/malaysia/article/shun-fatwas-from-politicians- muhyiddin-tells-muslims accessed May 5, 2013. 